\title{
The Long-Run Relationship among Health and Income in Mexico, 1940-2011
}

\author{
Vicente German-Soto ${ }^{1, *}$ and Martha Elena Fuentes Castillo \\ ${ }^{1}$ Faculty of Economics, Autonomous University of Coahuila, México \\ ${ }^{2}$ Socioeconomic Research Center (CISE), Autonomous University of Coahuila (Doctoral Program on \\ Regional Economics), México
}

\begin{abstract}
Theoretically, it has been argued the existence of not only a strong positive correlation among health and real per capita income, but also that their variations are highly interconnected. The stationarity among health indicators and income is analyzed for Mexico, allowing for the presence of multiple structural breaks along 1940-2011, with the aim to study its long-run relationship and how the reductions of the public expenditure have affected this link. One novelty is the long-run perspective supported on structural breaks that affect both the level and the slope of the time series. After the serial correlation is accounted for, several stationary processes evolving around a broken trend are found. The estimated breakpoints are widely related to events as crises and health system reforms, while the corresponding regimes changes lead to a stage of minor health expenditure. This last can be of concern to government and society if improvements on health and economic development are desired.
\end{abstract}

Keywords: Health economics, per capita income, cointegration, unit roots, structural breaks.

\section{INTRODUCTION}

The Mexican economy has not reached the sufficient economic growth and development to satisfy, at least, the growing of the population and its demand of employment and services in the most recent period. Since the nineties, the per capita gross domestic product (GDP) has exhibited rates of growth below to 3 percent yearly. In addition, this growing has not been uniform because it has been interrupted in more of one occasion by several recessions and crises. While eighties decade averaged a rate of growth of zero percent, by the middle of the nineties, the financial crisis (known as 'tequila crisis') brought negative rates of growth by 1995 and 1996, while for 2001, 2002 and 2003 the nation experienced a growing very near to one percent, in average; between 2009 and 2011 the economic growth again was impacted by the international real state crisis. In average, since the middle of the eighties the economic growth is below to 2.4 percent yearly, an insufficient economic performance to create the employments and satisfy the public expenditure required by the country. As a result, the government applied a policy of reducing of the public expenditure; in particular, the health public spending has been widely diminished since the eighties.

What are the consequences of this adverse panorama? Effects are not few: social and economic problems, income inequality, poverty and insufficient

*Address correspondence to this author at the Faculty of Economics, Autonomous University of Coahuila, Unidad Camporredondo, Edificio "E", Planta Baja, entre las calles Av. De los Maestros y David Berlanga, C.P. 25000, Saltillo, Coahuila, México; Tel: +52 8444128782 ;

Fax: +52 84441026 79; E-mail: vicentegerman@uadec.edu.mx

E-ISSN: 1929-7092/16 resources to replace and update the public infrastructure, a deteriorated productive efficiency, among others.

The aim of this research is to study the long-run equilibrium relationship among health and income level and how this linkage has been affected by the problems of low economic growth and reduction of the public expenditure.

We start from the theoretical precept that health and income level of any economy sustains a positive link in the long-run. ${ }^{1}$ At this respect, literature has argued that there is not only a strong positive correlation between health and income, but also that the income explains a high percentage of the health variation. However, this relationship not necessarily was stable because of several events modifying the trend and therefore the equilibrium path. If it so, then it is possible than time series was affected by the presence of structural breaks that, in turn, could have led the relationship to another level of equilibrium.

Methodology is based on the time series approach with structural breaks. It consists in the analysis of the long-run statistical properties of one variable through the concept of unit root. If the time series has unit root, it is not stationary and it is concluded that it has not an equilibrium behavior. If the null hypothesis of unit root is rejected, it is concluded that time series is in

${ }^{1}$ Seminal works about this relationship may be Mushkin (1962), Fuchs (1972), Grossman (1972) and Newhouse (1977), among others.

〔C 2016 Lifescience Global 
equilibrium. In addition, if this hypothesis is contrasted with the presence of structural change it is possible to give an idea about the stationarity of the time series with regime shift.

Due to the long-run perspective, our database is quite restrictive. Therefore, the evidence is only supported in five indicators of health on which were possible to collect annual information along 1940-2011. These variables are: child mortality rate $(\mathrm{CMR})$, maternal mortality rate (MMR), per capita health spending (pcHS), health spending as share of the GDP (HS-GDP) and life expectancy (LE). As a proxy of income level the per capita GDP is used.

Our results are in line with the theory for the link among per capita income with CMR, MMR and pcHS. However, HS-GDP and LE seem to be affected by more than two structural breaks and also by an adverse policy of budget cut that impacts the equilibrium path. Possible explanations about this last result also are illustrated.

Besides this introduction, the exposition is in six sections. The first one corresponds to the theoretical background. Second section presents a reviewing of the empirical evidence, while third section exposes the database and analyzes the variables. Fourth section explains the methodology, while the fifth section comments about the main results. Finally, sixth section concludes.

\section{THE THEORETICAL CONNECTION AMONG HEALTH AND INCOME}

In economic theory, it has been discussed the importance of economic growth and which elements or factors determine it. In the neoclassical theory the role of physical capital in the production process was emphasized, while the authors of endogenous growth added new elements to the debate as the role of the human capital, the innovation, the spending on research and development, and others more. In this line of analysis, the health condition outstands as one of the key determinants contributing at the production level of the countries. The argument for this is that a population in good health contributes to a higher production.

An initial theoretical approach was shown in Mushkin (1962), who believed a good health has two features: firstly, healthy people is more productive and can even improve the income level. Secondly, this new level of income would allow higher levels of health.
While Fuchs (1972) established the inverse relationship, because first there is a need to have better health levels and subsequently, due to the level, productivity increases. Moreover, Grossman (1972) specified a theoretical model of health in dual form, initially as a 'good consumption' by the demand for care health services, medicines and other goods and services that people is willing to consume with the end to recover the health status and, secondly, as a 'good investment' by the propensity of time and effort that families spend preventing, monitoring and improving their health, such as nutrition, exercise and recreation. More recently, Barro (1996) and Bloom, Canning and Sevilla (2004) incorporated the importance of health in the economy in neoclassical models of economic growth with human capital.

Van Zon and Muysken (2001) established a theoretical model in which health, as well as the accumulation of knowledge, impacts the labor factor and thus the economy. Howitt (2005) suggested that a relationship between health and economic growth must consider the process of international technology transfer. It consists in a process of creative destruction of products that provides countries with the comparative advantages, while disadvantaged countries can be benefited from technological innovations that others develop. The impact of health on economic growth, according to Howitt, would be through six main channels: production efficiency, life expectancy, learning ability, creativity, ability to adapt to difficult situations and inequality.

These theoretical approaches lead to consider the existence of a relationship between health and economic growth. However, the direction of this causality relationship it is not completely definitive, if health conditions influence the economic growth or if economic growth determines the health status of the population or, perhaps, if both are in a causal bidirectional relationship.

The fact is that, at least theoretically, a dependency and a close relationship exist between economic growth and health, which is explained by the complementarity nexus between them. This is so, especially in long-run relationships because of the existence of an accumulative effect that is reinforced over time.

\section{EMPIRICAL EVIDENCE: A REVIEW OF LITERATURE}

Among the first theoretical approaches of the nexus between health and economic growth were established 
by Mushkin (1962), Fuchs (1972) and Grossman (1972) who argued about the positive relationship between economy and health. Later, using health indicators such as life expectancy, mortality rates, health expenditures, among others, the studies focused on determining the effect of health on economic growth through production functions in which health was incorporated as an explanatory variable.

A more recent reviewing of the literature highlights convergent outcomes on a positive relationship. Arora (2001) showed a positive impact of life expectancy on economic growth between 30 and 40 percent in industrialized countries. About the effects of mortality, Lorentzen, McMillan and Wacziarg (2008) analyzed a group of countries including Sub-Saharan African countries and found that endemic diseases and geographical characteristics of countries affect both maternal and infant mortality and subsequently physical capital and labor are affected and, finally, through this channel the economic growth is impacted. Also they consider that these evidences explain the situation in that part of Africa. Other studies such as health spending and growth were also positive, as Chang and Yung-Hsiang (2006) who studied 15 countries in the Organization for Economic Cooperation and Development (OECD) for the period 1980-2008, the outcome confirmed that health spending contributed to the growth of those countries, however, the expenditure on health was considered as a luxury good'. Adeniyi and Abiodun (2011) found that health spending must be efficient to contribute to economic growth in Nigeria.

Instead of a production function, a different body of research emphasizes on the stochastic properties of the time series. Under this new branch of studies, the possible spurious results in the relationship between health and economic growth are discarded. The findings have found a long-run relationship, which has changed in time. A set of studies between health spending and growth has confirmed cointegration in the long-run. For example, Rao, Jani and Sanjivee (2008) used the nexus among them to analyze the quality of life in the countries of the Association of Southeast Asian Nations. The results were favorable, pointing that in the long-run there are improvements in the quality of life. For a group of oil-producers countries, Mehrara and Musai (2011) incorporate oil revenues besides health spending and economic growth to confirm a dependence relationship of these last on the first between 1971 and 2007. Moreover, Tang (2012) also found a balanced relationship between health expenditures and growth in Malaysia. The author also noted that 1970-2007 spending on health was a 'luxury good'.

In addition, positive findings were reported for Algeria and the United States. In the first case a longrun cointegration relationship was confirmed by Boussalem, Boussalem and Taiba (2014). In the second case, Bukenya (2009) analyzed the states of Alabama, Georgia, Louisiana, Mississippi and Tennessee. The evidence confirmed that only Georgia showed a balance in both indicators, moreover, a feedback effect such as long-run bidirectional causality between health expenditure and growth.

Also, health indicators have been diverse. For example, Sirag, Adamu and Norashidah (2013) used life expectancy to show that there was a balanced relationship between health and economic growth in Sudan along 1980-2010. In Kumar (2015) the life expectancy, the spending on health and the child mortality were considered to show a positive relationship with economic growth in India between 1960 and 2008.

The presence of structural changes in the modeling of the health-income relationship had not been taken into account in the previous evidences. However, considering the long-run periods, the role of structural changes becomes relevant because could appear atypical events that modify the path of the series, and could lead to spurious results when in fact they are not taking into account. Such is the proposal of Jewell, Lee, Tieslau and Strazicich (2003) and Carrion-iSilvestre (2005) who analyzed the nexus between health spending and real per capita output in OECD countries. They found an equilibrium path after to control by some breaks. More recent works within this same line are Chen (2013), who investigated the convergence in health financing in eight countries, and Pekkurnaz (2015) who analyzed 22 OECD countries. These last two works showed convergence in most of the cases, but only when the structural change was included.

Finally, also there is some evidence for Mexico, although the structural changes of the long-run have not been sufficiently boarded. Mayer, Mora, Cermeño, Barona and Duryeau (2003) found a positive relationship. Augments of life expectancy at birth increased in two percent the economic growth between 1965 and 1995. Other studies are focused on the role of the public expenditure, as Lustig (2007), who 
suggests major health expenditure with the aim to confront the social sectors problems. Pinzon-Florez, Reveiz, Idrovo and Reyes (2014), who evaluated the effect between public spending on health, inequality and marginalization index, found that federal funding exerts a positive effect on the performance of the health indicators.

\section{DATABASE AND PRELIMINARY ANALYSIS}

\subsection{Description of Variables}

The income level is approached as the per capita GDP, in constant terms, and it is obtained from official statistics generated by INEGI (National Institute of Statistics). A homogenous and long-run time series of GDP only is available from German-Soto (2005). This database is supported in data from INEGI and avoids the typical troubles to treat with different base year because the author has done an important task of homologation and so all the 1940-2011 period can be reflected under one same price, in 1993 Pesos.

As for health, five indicators were possible to get for the same period: child mortality rate (CMR), maternal mortality rate (MMR), life expectancy (LE), per capita health spending ( $\mathrm{pcHS}$ ) and health spending as ratio of GDP (HS-GDP).

Data for CMR, MMR and LE is based on national statistics and population estimates collected by several institutes, as the Mexican Ministry of Health (Secretaría de Salud, SSA), INEGI and the National Council on Population (CONAPO). CMR is calculated as the percentage of child mortality by each one thousand was born alive yearly, and the estimates were provided from the statistical yearbooks of INEGI (several years). MMR is defined as maternal mortality by each 100,000 live births and the sources are INEGI (2009) and the maternal mortality observatory of the Ministry of Health (SSA). Life expectancy corresponds to statistical on population derived by INEGI and also reported by the World Bank. Finally, health public spending is obtained from INEGI (2009) and statistical yearbooks of INEGI. Figures were calculated in real terms through the use of the implicit deflator of the product. After that, they were relativized in per capita terms (pcHS) and as share of the national GDP (HS-GDP).

In spite that these statistics are quite complete and truthful, some details were necessary in the aim to have a homogenous and sufficiently large database. First, the health spending only covers the federal government budget on health; in addition, the health care of the Mexican Oil Institute (PEMEX) is excluded from this total because it is not representative for all the period: figures start by 1993 and only cover the three percent of the insured population. Secondly, for initial years the health spending by the Mexican Social Security Institute (IMSS), SSA and the Security and Social Services Institute for State Workers (ISSSTE) was extrapolated because they were created after 1940 (IMSS, in 1944; SSA, in 1947, and ISSSTE, in 1961). Some gains of methodological efficiency are obtained without to affect the tendency. An exercise of backward simulation until 1940 was carried out to complete the empirical analysis. This period is relatively stable and not implies great changes in health spending, making easier our estimates.

\subsection{The Mexican Health System: A Description}

The health system in Mexico is integrated by public and private institutes. Basically, public health services are offered by SSA, IMSS, ISSSTE, PEMEX and those corresponding at the medical centers of the Mexican Army. Financing of these institutes is provided by the federal government and health cares are directed to a wide population. By its coverage, the main institute is the IMSS. Often the data of insured population of this dependency is considered as reference of the Mexican economy formality.

Private health services are supplied by profit institutes and the target population is that with the enough income for medical expenses. Some studies have determined that this concept of cost contributes as additional cause for impoverishment of the families with scarce income resources (Knaul, Arreola-Ornelas, Méndez-Carniado and Martínez 2005a; Knaul, ArreolaOrnelas, Méndez-Carniado, Bryson-Chan, Barofsky, Maguire and Sesma 2007, among others). Figure 1 highlights the structure of the health Mexican system.

In the modern era, the health care services in Mexico have experienced, at least, three important reforms. In the first one, occurred between 1940 and 1970, the main health institutes were created: SSA, IMSS and ISSSTE. By 1994, these institutes attended at the 89 percent of the population, while the other 11 percent was without access to services (Frenk, Sepúlveda, Gómez-Dantés and Knaul, 2003).

A second reform is identified from decentralization of the population health services through the transference of some administrative responsibilities 


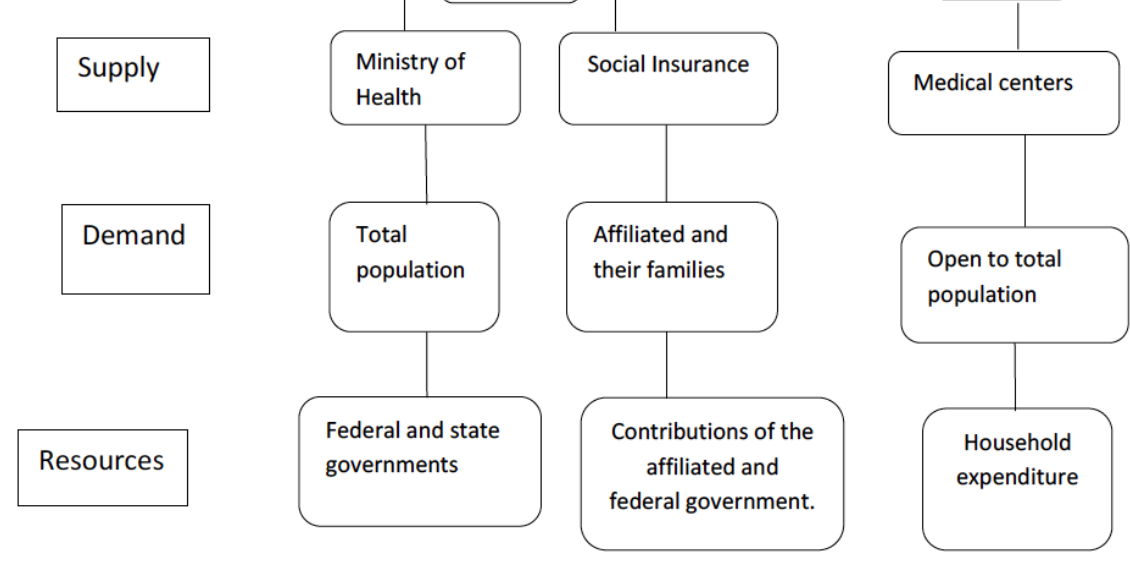

Figure 1: The scheme of health services in Mexico.

Source: own elaboration.

from federation to state governments. This process was given in two stages. In the first one only 14 states were added at this agreement (between 1985 and 1987). In the second stage, by 1996, all states were integrated at the decentralization program. The reform was a more complete transference of responsibilities and financial autonomy (Merino, 2003).

The third reform is recognized by beginnings of the decade of two-thousands and it is symbolized by several social programs linked with the sanitary system: PROGRESA, IMSS-OPORTUNIDADES,
Popular Insurance Program (Programa de Seguro Popular, PSP), among others, directly targeted to population with the lower incomes. Some studies have found that PSP has resulted in an important reduction of the health care spending of the Mexican families (Knaul, Arreola, Borja, Méndez-Carniado and Torres 2003, Knaul et al. 2005a, Knaul, Arreola-Ornelas and Méndez-Carniado, 2005b and Knaul et al. 2007).

Health care services have importantly improved in part due to drag effect by the international medical and technological advances (Acemoglu and Jhonson,

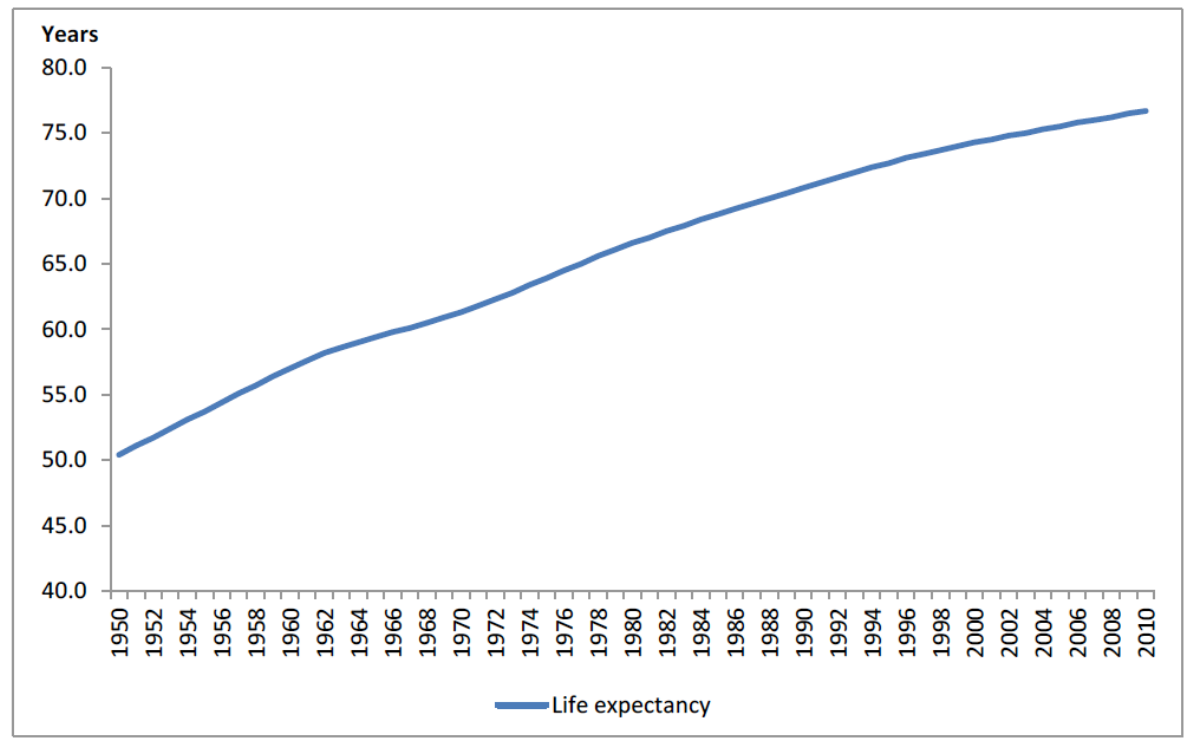

Figure 2: Life expectancy in Mexico, 1950-2011.

Source: own elaboration. 


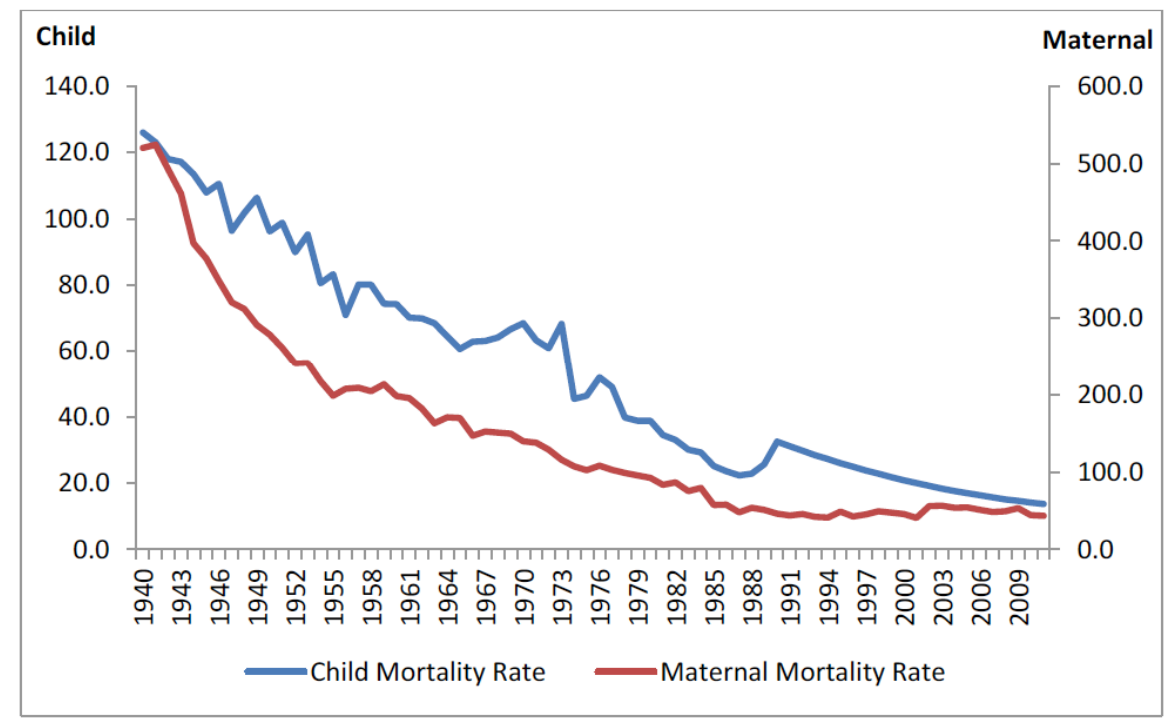

Figure 3: Child and maternal mortality rates in Mexico, 1940-2011.

Source: own elaboration.

2007). In particular, life expectancy has registered great increases in Mexico in the last sixty years. It has gained around 25 years (Figure 2): actually the index is about of 77 years for women and 72 for men (INEGI, 2013 and the World Bank, 2014).

While the overall mortality rate presents a notable reduction between 1940 and 2011 to pass of 22.8 to 4.9 by each one thousand inhabitants, the child mortality exhibited a reduction of 126 in 1940 to 13.7 in 2011. As for MMR, it was of 520 deaths at beginning of the period to only 43 deceases in 2011 (Figure 3).
The health spending indicators describe similar trajectories along the period, but only until final of the nineties, when pcHS continuously rose while HS-GDP remained almost without tendency (Figure 4). The indexes seem to describe those episodes of crises in the eighties, the 1994 international crisis and the recession of the 2000 year. Impacts of the most recent crisis, in 2008, are clearer on the HS-GDP series because of the great fall of the Mexican GDP between 2008 and 2010.

International comparisons indicate that Mexico has been surpassed in health performance by not only

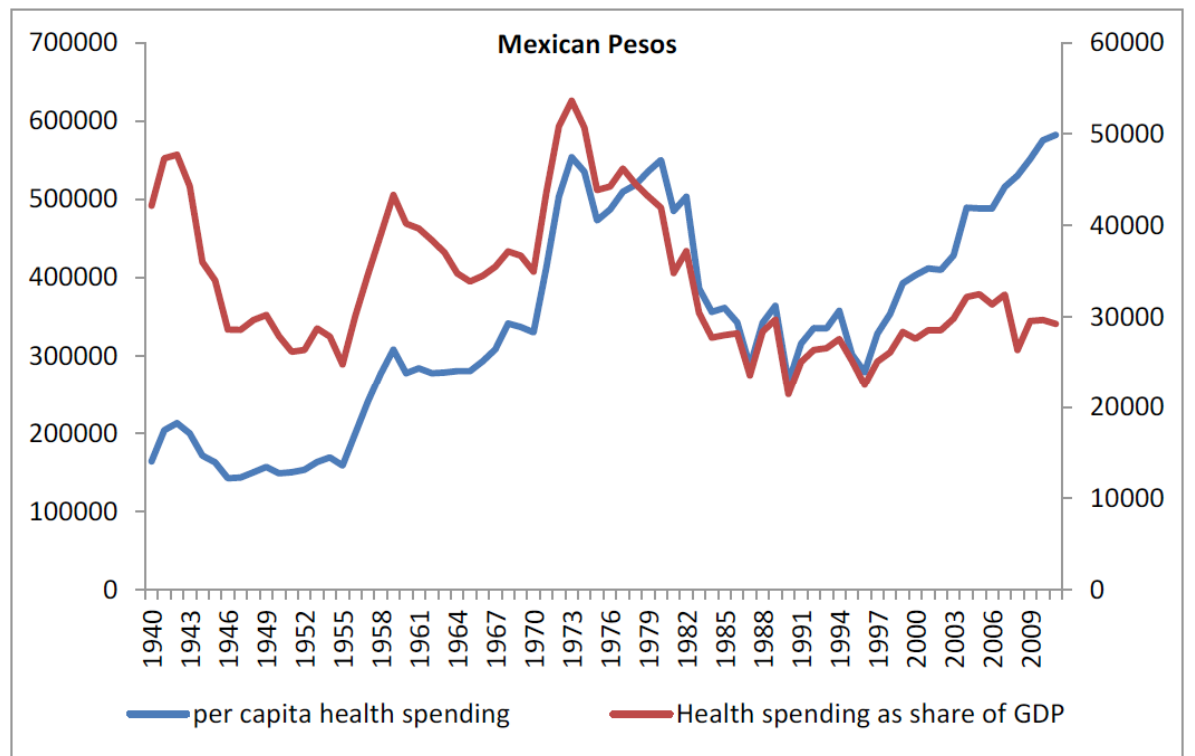

Figure 4: Indexes of health spending, 1940-2011.

Source: own elaboration. 
similar income Latin American countries, but also by other even with lower income, such as Chile, Costa Rica, Cuba, Dominican Republic and Panama.

In particular, for health spending is also surpassed by Brazil, Honduras and Paraguay; in child mortality by Argentina, Brazil and Uruguay. In resume, Mexico is below of other Latin American countries considered as similar in many aspects (World Bank, 2014). This result suggests that improvements in health care in Mexico are neither exclusive nor sufficient to reach an optimum level of development and it should be a concern matter because of the advances in health can be obeying to the 'international drag effect' but not so by own performance.

\subsection{The Mexican GDP in the Long-Run}

From a long-run perspective the per capita GDP of Mexico has been marked by at least two great structural changes. They have been as strong as to modify the trend and remove it from its equilibrium path. Along 1940 and 1982 Mexico exhibited a stage of solid economic progress, reflected in rates of per capita GDP growth between four and nine percent yearly. This stage was dominated by a strong state intervention in the economy. The government role was mainly directed to the creation of the basic conditions for the development, as investments in physical infrastructure (roads, electricity, hydraulic infrastructure, hospitals, schools, among others), and also during this stage the great social and economic institutes were created (IMSS and ISSSTE are some examples). The government also carried out a policy of protection of the shining industry through strong tariffs on imports and establishing a policy of internal prices where the primary sector supported the industry with cheap inputs. As a result, this stage was known as the Mexican sustainable development or as 'the Mexican miracle' by some authors (Hernández Laos, 1992 and 2000). However, at the start of the eighties the growth model showed signs of exhaustion: several macroeconomic problems as monetary, excessive inflation, strong currency depreciations and increments of the external debt, which led to a huge crisis with depth social and economic consequences. As a result, economy exhibited very low and also negatives rates of growth for some years. Eighties were characterized by nulls rates of growth, in average, and the economic recovery was achieved until beginnings of the nineties. In terms of per capita GDP, this second stage seems to go from 1982 to 1994-1995, when a sudden crisis overshadowed the slow economic recovery started some years ago. The Figure $\mathbf{5}$ draws this trend in per capita GDP. Roughly, the per capita GDP evolution seems to highlight a path with three regime shifts identified from two structural changes. The first structural change may be located at the start of the eighties and by 1994-1995 the second one.

The added vertical straight lines in the Figure $\mathbf{5}$ approximately specify the probable location of the breakpoints that divide the trajectory in three regime shifts. It is notorious how the per capita GDP path can be reproduced by simple straight lines signaling the three commented regime shifts. The first one

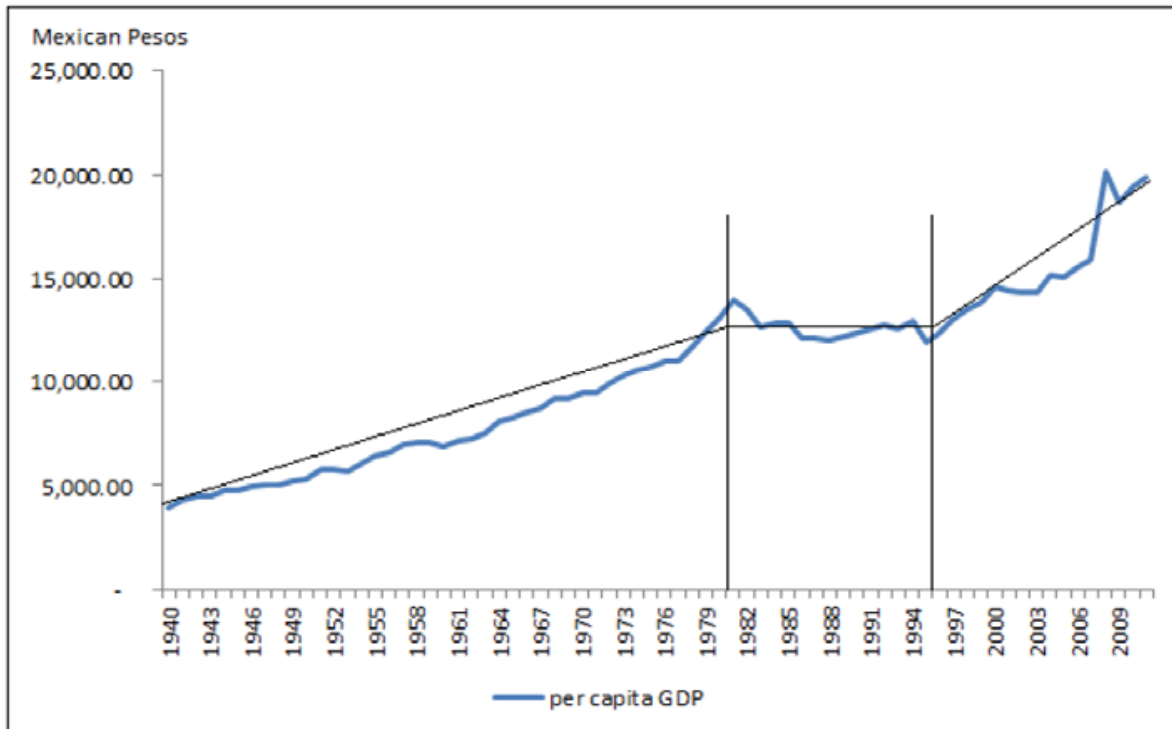

Figure 5: Per capita GDP of the Mexican economy, 1940-2011. 
experienced a positive slope, near to zero, the second, and again a positive trend is illustrated in the last and most recent regime.

\section{METHODOLOGY: STOCHASTIC TESTS WITH STRUCTURAL BREAKS}

Some assumptions about statistical properties of the variables are more relevant in the long-run: for instance, some aspects of serial correlation, the presence of events modifying the trend and the possibility of spurious relations. Therefore, one appropriate methodology is the time series analysis with structural breaks. It seeks to test if one set of values, evolving in time, have a stable conduct, that is, if it is stationary. As consequence that variables are affected by structural changes, the stationarity is possible to reach considering that this evolution changed in one point in the time. So, the methodology is based on the time series analysis with structural changes.

The time series analysis is supported in the statistical properties of mean, variance and covariance of the variables. Theoretically, these properties should be constant in time and their values only depend of the interval of time where they are measured. Then, stochastic and stationaries properties are present in $X$ if,

Mean: $E\left(X_{t}\right)=\mu$

Variance: $\operatorname{Var}\left(X_{t}\right)=E\left(X_{t}-\mu\right)^{2}=\sigma^{2}$

Covariance: $\gamma=E\left[\left(X_{t}-\mu\right)\left(X_{t+k}-\mu\right)\right]$

Actually, there is a great variety of tests to infer about the stationarity of a time series based on the analysis of the properties shown by equation (1). On the one hand some popular tests in the literature are supported in parametric estimates of the variance: $A D F$ (augmented Dickey-Fuller), based on the original idea of Dickey and Fuller (1979), the KPSS of Kwiatkowsky, Phillips, Schmidt and Shin (1992), the test of optimum point of Elliot, Rothenberg and Stock (1996), the ADFGLS of Elliot, Rothenberg and Stock (1996), among others. On the other hand some tests are based on non-parametric estimates: the $Z$ tests of Phillips and Perron (1988) and the modified tests of $\mathrm{Ng}$ and Perron (2001). All they seek to contrast if one time series is characterized by unit roots. With this purpose the parametric proposals estimate a regression equation as the next:
$\Delta x_{t}=c+\beta t+\delta x_{t-1}+\sum_{j=1}^{k} \varsigma_{j} \Delta x_{t-j}+\varepsilon_{t}$

where $x$ is the variable of interest, $\Delta$ indicates first difference, $t$ is the linear trend, $c$ is the constant term, $\delta$ $=(\rho-1)$ and the sum of $k$ coefficients have the aim to reduce the problem of serial correlation. If $\delta=0$ the time series has unit root, if $\delta<0$ then it is stationary around a linear trend. This specification is known as the $A D F$ test and the inference on stationarity is obtained assessing the significance of $\delta$ :

$$
\tau=\frac{\hat{\delta}}{\text { s.e. }(\hat{\delta})}
$$

where s.e. is the standard error of the estimated value of $\delta$. Due to inclusion of the dependent variable at the right side of the equation (2) the coefficients have not a normal distribution and the inference must be based on critical values of $\tau$ calculated through Monte Carlo simulations.

A key aspect with the specification in (2) is to find the optimum number of lags $(k)$ to treat with serial correlation. Some authors recommend some information criterion as Akaike or Schwarz. In addition, Phillips and Perron (1988) consider that the use of nonparametric estimates of the variance avoids the problem to decide on the $k$ lags and derive two alternative tests:

$Z_{\alpha}=T(\hat{\rho}-1)-\frac{T^{6}}{24 D_{x}}\left(S^{2}-S_{\varepsilon}^{2}\right)$

$Z_{t}=\frac{S_{\varepsilon}}{S} t \hat{\rho}-\frac{T\left(S^{2}-S_{\varepsilon}^{2}\right)}{4 \sqrt{3 D_{x} S}}$

where $Z_{\alpha}$ and $Z_{t}$ correspond at the specifications including constant and linear trend, respectively, $S^{2}$ and $S_{\varepsilon}^{2}$ are variances in the long and short term, respectively.

Alternatively, Kwiatkowski et al. (1992) develop a test as the sum of the walk random, deterministic trend and stationary errors. They reverse the null hypothesis and define under the Ho that time series is stationary, so in the alternative one the time series presents unit root or non-stationary. Their proposal is defined as:

$\operatorname{KPSS}=\frac{1}{T^{2}} \frac{\sum_{t=1}^{T} S_{t}^{2}}{\hat{\sigma}_{\infty}^{2}}$ 
where $\hat{\sigma}_{\infty}^{2}$ is the long-run variance. To obtain a consistent estimator of the variance and the selection of the optimum lag, they propose the Newey and West (1987) definition. The debate on the null hypothesis, as stationary or as unit root, also motivated the idea of Elliot, et al. (1996) to propose the known as optimal point or ERS-GLS test:

$$
P_{T}=\frac{[S(\bar{\alpha})-\bar{\alpha} S(1)]}{\hat{w}^{2}}
$$

where $\hat{w}^{2}$ is the estimator of long-run variance. Details about the estimation of (6) by ordinary least squares and generalized least squares (ERS-GLS) are given in Elliot, et al. (1996).

Lastly, $\mathrm{Ng}$ and Perron (2001) develop a set of tests (known as $M$-tests) that modify the original proposal of Phillips and Perron (1988). They propose some modifications consistent in the incorporation of spectral variances in the estimators and the selection of the lags to reduce serial correlation. Their proposal is defined as follows:

$$
\begin{aligned}
M Z_{\alpha} & =\left(T^{-1} x_{T}^{2}-S_{A R}^{2}\right)\left(2 T^{-2} \sum_{t=1}^{T} x_{t-1}^{2}\right)^{-1} \\
M S B & =\frac{T^{-2} \sum_{t=1}^{T} x_{t-1}^{2}}{S_{A R}^{2}} \\
M Z_{t} & =M Z_{\alpha} \times M S B
\end{aligned}
$$

where $M Z_{\alpha}$ and $M Z_{t}$ are the modified proposals of Phillips and Perron (1988), while MSB corresponds to a specification that improves the contrast of Bhargava (1986).

If this set of contrasts does not find stationarity is because of series would be characterized by macroeconomic events that changed its relationship along time, as a consequence these tests are not adequate because they were not defined when series is dominated by structural changes.

Perron and Vogelsang (1992), Zivot and Andrews (1992) and Lumsdaine and Papell (1997) developed the structure of unit root test that takes into account the presence of one and two structural breaks. In this case equation (2) should be modified to contemplate the effects of one or more structural changes. The final proposal can be expressed by the next general specification:

$$
\begin{aligned}
& x_{i, t}^{*}= \mu_{i}+\beta_{i} t+\sum_{j=1}^{m} \theta_{i, j} D U_{i, j, t}+\sum_{j=1}^{m} \gamma_{i, j} D T_{i, j, t}+\sum_{j=1}^{m} d_{i, j} D(T b)_{i, j, t} \\
& \alpha_{i} x_{i, t-1}^{*}+\sum_{j=1}^{k} c_{j} \Delta x_{i, t-j}^{*}+\varepsilon_{i, t}
\end{aligned}
$$

where $x_{i, t}^{*}$ denotes the gap between income and each indicator of health in the present exercise, $D U_{i, j, t}=1$ and $\quad D T_{i, j, t}=\left(t-T b_{i, t}\right)$ for $t>T b_{i, j}, \quad 0 \quad$ elsewhere; $D(T b)_{i, j, t}=1$ for $t=\left(T b_{i, j, t}+1\right)$ and 0 elsewhere, and where $T b_{i, j, t}$ defines the $j$-th $(j=1, \ldots, m)$ structural breakpoint for the $i$-th time series. The order of the autoregressive correction in equation (8) has been chosen with the $t$-sig criterion in $\mathrm{Ng}$ and Perron (1995) and for this work a value of $k_{\max }=8$ is considered as the maximum lag.

If $\beta$ and $d_{i, j}$ are zero in (8) then the model of two structural breaks of Lumsdaine and Papell (1997) is obtained (model labeled as $A A$ ), while if $m$ is equal to one, then model $A$ of Zivot and Andrews is estimated. If also we eliminate the $y$ 's coefficients, then a data generating process only evolving around a constant is obtained (the models of Carrion-i-Silvestre, Artís and Sansó, 2004: $A n$, for one break, and $A A n$, for the case of two breaks). Finally, the complete expression (8) is the proposal of two structural breaks by Lumsdaine and Papell (1997), that is, the model labeled as CC, while if only one structural break is selected, then we have their specification known as $C$ in the specification (8).

Since we cannot to know the data generating process of each variable, different specifications have been essayed, while in the selection of the one of the best adjustment we follow the criterion of Montañés, Olloqui and Calvo (2005) and select the type of the break, that is, the models $A, A n, C, A A, A A n$ and $C C$, using the Bayesian Information Criterion (BIC). Moreover, for some time series the null hypothesis of unit root is not rejected with some of these specifications (models $A, A A, A n, A A n, C$ and $C C$ ) it would be valuable essay with all them and select that of the best adjustment.

\section{ESTIMATES AND ANALYSIS OF THE RESULTS}

The methodology of time series is applied on the gap among per capita GDP and each indicator of health: CMR, MMR, LE, pcHS and HS-GDP. If distance among them is constant along the period, even in each regime originated by the breaks, then the variables evolve around an equilibrium path, that is, they are 
stationaries with structural breaks occurring in one moment of the period. The gap is measured through the logarithmic differences of the variables and then the set of unit roots tests with structural breaks are applied on these values.

However, before to present the results with structural breaks it will be interesting to report the estimates with standard unit root tests; that is, the unit root tests without structural breaks. They are: $A D F$, ADF-GLS, KPSS, PP, ERS, $M Z_{\alpha}, M Z_{t}, M S B$ and MPT. As was exposed before, this set of tests has the advantage to be based on different criteria on the DGP, some of them are supported on non-parametric tests, other more are based in GLS and, finally, the statistics modified by $\mathrm{Ng}$ and Perron (2001).

All the tests in Table 1 confirm the presence of unit roots on the five relations among health indicators and per capita GDP. The results are robust also for the two assumed deterministic terms: the constant and the linear trend. Results from the Table $\mathbf{1}$ are quite conclusive: the relationships are not stationaries. However, from the exploratory analysis we see that variables are dominated by changes along the time. Then, the presence of structural changes possibly is hiding the stationarity.

In the exploratory analysis was highlighted that some events related to the real economy and also to reforms on the health system could be affecting the long-run link among the analyzed variables. Therefore, we estimate the equation (8) in its several alternatives and models.

Table 2 reports the results of best adjustment for each indicator according to the Bayesian information criterion (BIC). It seems that the alternative of two structural changes is the best option to describe the behavior among the indicators of health and per capita GDP.

Table 1: Unit Root Tests in the Health-Per Capita GDP Gap

\begin{tabular}{|c|c|c|c|c|c|c|c|c|c|c|}
\hline & \multirow{2}{*}{ CMR } & \multirow{2}{*}{ MMR } & \multirow{2}{*}{ LE } & \multirow{2}{*}{ pcHS } & \multirow{2}{*}{ HS } & \multicolumn{5}{|c|}{ Result } \\
\hline & & & & & & CMR & MMR & LE & pcHS & HS \\
\hline \multicolumn{11}{|l|}{ Constant } \\
\hline$Z a$ & 1.59 & 1.06 & 1.35 & -5.40 & 1.39 & $\mathrm{I}(1)$ & $\mathrm{I}(1)$ & $\mathrm{I}(1)$ & $\mathrm{I}(1)$ & $\mathrm{I}(1)$ \\
\hline$M Z a$ & 1.86 & 1.33 & 1.75 & -5.08 & 1.68 & $\mathrm{I}(1)$ & $\mathrm{I}(1)$ & $\mathrm{I}(1)$ & $\mathrm{I}(1)$ & $\mathrm{I}(1)$ \\
\hline$M Z t$ & 3.04 & 2.36 & 1.36 & -1.52 & 2.62 & $\mathrm{I}(1)$ & $\mathrm{I}(1)$ & $\mathrm{I}(1)$ & $\mathrm{I}(1)$ & $\mathrm{I}(1)$ \\
\hline$M S B$ & 1.63 & 1.77 & 0.77 & 0.300 & 1.55 & $\mathrm{I}(1)$ & $\mathrm{I}(1)$ & $\mathrm{I}(1)$ & $\mathrm{I}(1)$ & $\mathrm{I}(1)$ \\
\hline$P_{T}$ & 286.90 & 318.62 & 75.50 & 6.20 & 265.51 & $\mathrm{I}(1)$ & $\mathrm{I}(1)$ & $\mathrm{I}(1)$ & $\mathrm{I}(1)$ & $\mathrm{I}(1)$ \\
\hline$M P_{T}$ & 205.61 & 218.82 & 51.23 & 4.99 & 182.21 & $\mathrm{I}(1)$ & $\mathrm{I}(1)$ & $\mathrm{I}(1)$ & $\mathrm{I}(1)$ & $\mathrm{I}(1)$ \\
\hline$A D F-G L S$ & 2.61 & 1.88 & 1.05 & -1.62 & 2.17 & $\mathrm{I}(1)$ & $\mathrm{I}(1)$ & $\mathrm{I}(1)$ & $\mathrm{I}(1)$ & $\mathrm{I}(1)$ \\
\hline KPSS & 717.18 & 772.01 & 107.31 & 7.63 & 550.65 & $\mathrm{I}(1)$ & $\mathrm{I}(1)$ & $\mathrm{I}(1)$ & $\mathrm{I}(1)$ & $\mathrm{I}(1)$ \\
\hline$k$ & 0 & 0 & 0 & 0 & 0 & & & & & \\
\hline \multicolumn{11}{|l|}{ Linear trend } \\
\hline$Z a$ & -12.57 & -2.28 & -6.77 & -8.80 & -4.78 & $\mathrm{I}(1)$ & $\mathrm{I}(1)$ & $\mathrm{I}(1)$ & $\mathrm{I}(1)$ & $\mathrm{I}(1)$ \\
\hline$M Z a$ & -11.41 & -1.81 & -6.26 & -8.22 & -4.35 & $\mathrm{I}(1)$ & $\mathrm{I}(1)$ & $\mathrm{I}(1)$ & $\mathrm{I}(1)$ & $\mathrm{I}(1)$ \\
\hline$M Z t$ & -2.38 & -0.78 & -1.73 & -2.02 & -1.47 & $\mathrm{I}(1)$ & $\mathrm{I}(1)$ & $\mathrm{I}(1)$ & $\mathrm{I}(1)$ & $\mathrm{I}(1)$ \\
\hline$M S B$ & 0.21 & 0.43 & 0.27 & 0.24 & 0.33 & $\mathrm{I}(1)$ & $\mathrm{I}(1)$ & $I(1)$ & $\mathrm{I}(1)$ & $\mathrm{I}(1)$ \\
\hline$P_{T}$ & 8.04 & 44.93 & 15.03 & 10.99 & 23.98 & $\mathrm{I}(1)$ & $\mathrm{I}(1)$ & $\mathrm{I}(1)$ & $\mathrm{I}(1)$ & $\mathrm{I}(1)$ \\
\hline$M P_{T}$ & 7.99 & 38.74 & 14.52 & 11.87 & 20.90 & $\mathrm{I}(1)$ & $\mathrm{I}(1)$ & $\mathrm{I}(1)$ & $\mathrm{I}(1)$ & $\mathrm{I}(1)$ \\
\hline$A D F-G L S$ & -2.62 & -0.90 & -1.87 & -2.16 & -1.62 & $\mathrm{I}(1)$ & $\mathrm{I}(1)$ & $\mathrm{I}(1)$ & $\mathrm{I}(1)$ & $\mathrm{I}(1)$ \\
\hline KPSS & 1.22 & 13.88 & 3.05 & 2.29 & 8.02 & $\mathrm{I}(1)$ & $\mathrm{I}(1)$ & $\mathrm{I}(1)$ & $\mathrm{I}(1)$ & $\mathrm{I}(1)$ \\
\hline$k$ & 0 & 1 & 0 & 0 & 0 & & & & & \\
\hline
\end{tabular}

Note: the null hypothesis indicates a unit root against the alternative of stationarity, except for MSB test, where the hypotheses are reverted. The lags number ( $\mathrm{k}$ ) is optimally selected with the Modified Bayesian Information criterion (MBIC) of Ng and Perron (2001), the maximum lags are equal to 5. For a constant, the critical values are (5\%): $\mathrm{Z \alpha}-8.35, \mathrm{MZ \alpha}-8.1, \mathrm{MZ}_{\mathrm{t}}-1.98, \mathrm{MSB} 0.233, \mathrm{P}_{\mathrm{t}}$ and $\mathrm{MP}_{\mathrm{t}} 3.17$ and $\mathrm{ADF}-\mathrm{GLS}-1.98$. For a linear trend, the critical values are $(5 \%)$ : $\mathrm{Z} \alpha$ and $\mathrm{MZ} \alpha-17.3$, MZt -2.91, MSB 0.168, $P_{t}$ and $M P_{t} 5.48$ and ADF-GLS -2.91. I(1) indicates that time series has a unit root. 
Table 2: Unit Root Tests with Multiple Structural Breaks in the Health-Per Capita GDP Gap

\begin{tabular}{|c|c|c|c|c|c|c|c|c|c|c|}
\hline Variable & Model & $\begin{array}{l}\text { TB1 } \\
\text { TB2 }\end{array}$ & $\mu$ & $\beta$ & $\theta_{1}$ & $\theta_{2}$ & $\gamma_{1}$ & $\gamma_{2}$ & $\mathbf{t}_{\alpha}$ & $k$ \\
\hline CMR & $\mathrm{CC}$ & $\begin{array}{l}1969 \\
1989\end{array}$ & $\begin{array}{c}2.238 \\
(6.790)\end{array}$ & $\begin{array}{c}0.033 \\
(6.113)\end{array}$ & $\begin{array}{l}-0.017 \\
(4.238)\end{array}$ & $\begin{array}{c}-0.010 \\
(-2.425)\end{array}$ & $\begin{array}{c}-0.123 \\
(-2.532)\end{array}$ & $\begin{array}{c}-0.420 \\
(-6.279)\end{array}$ & $\begin{array}{c}-0.631 \\
(-6.607)^{*}\end{array}$ & 0 \\
\hline MMR & AA & $\begin{array}{l}1995 \\
2002\end{array}$ & $\begin{array}{c}1.501 \\
(-7.552)\end{array}$ & $\begin{array}{c}0.041 \\
(-6.873)\end{array}$ & $\begin{array}{l}-0.291 \\
(-6.000)\end{array}$ & $\begin{array}{c}-0.269 \\
(-4.906)\end{array}$ & & & $\begin{array}{c}-0.622 \\
(-7.026)^{*}\end{array}$ & 1 \\
\hline $\mathrm{pcHS}$ & AAn & $\begin{array}{l}1956 \\
1983\end{array}$ & $\begin{array}{c}1.620 \\
(5.314)\end{array}$ & & $\begin{array}{c}-0.152 \\
(-3.517)\end{array}$ & $\begin{array}{l}-0.163 \\
(4.613)\end{array}$ & & & $\begin{array}{c}-0.455 \\
(-5.283)^{*}\end{array}$ & 6 \\
\hline $\mathrm{HS}$ & AA & $\begin{array}{l}1985 \\
1993\end{array}$ & $\begin{array}{c}3.810 \\
(5.025)\end{array}$ & $\begin{array}{c}0.012 \\
(4.843)\end{array}$ & $\begin{array}{l}-0.115 \\
(-4.535)\end{array}$ & $\begin{array}{l}-0.065 \\
(-2.663)\end{array}$ & & & $\begin{array}{c}-0.454 \\
(-4.984)\end{array}$ & 0 \\
\hline LE & AAn & $\begin{array}{l}1963 \\
2004\end{array}$ & $\begin{array}{c}0.701 \\
(3.010)\end{array}$ & & $\begin{array}{c}0.049 \\
(2.217)\end{array}$ & $\begin{array}{c}0.063 \\
(3.100)\end{array}$ & & & $\begin{array}{c}-0.144 \\
(-2.956)\end{array}$ & 0 \\
\hline
\end{tabular}

Note: TB1 and TB2 denote the estimated breakpoints, t-values are in parentheses. Superscript * stands for rejection of the null hypothesis of unit root at the $10 \%$ or less of significance.

For CMR the selected model is that labeled as CC, that is, two structural breaks occurring in both mean and trend. The breakpoints were located by 1969 and 1989 , indicating that after to control by these dates the link describes a stationary process, according with the theory. It is highlighted that estimated coefficients of both dummies assessing the breakpoints of the series ( $\theta$ coefficients, for breaks on constant, and $V$ coefficients, for breaks on slope) are negative and highly significant. It is interpreted as a favorable result to the theory that predicts an augment of the gap among income level and child mortality rates.

After the estimated breakpoints, identified by 1969 and 1989, increases on per capita GDP reduced the child mortality rate. This impact was less depth after the second structural change because of the estimated coefficient of $2.21(2.238-0.027)$ is minor that its initial value of 2.238. A similar conclusion is reached in the relationship with maternal mortality rate (MMR), in the sense that also it follows a stable equilibrium, but only after two structural changes: 1995 and 2002. For this case the model of best adjustment is that labeled as AA. For this variable the increases on income led to reduce the MMR, in accordance with the theoretical expectation.

The health spending indicators estimated opposite results. While per capita health spending is stationary with two structural breaks, 1956 and 1983, according to the model AAn, the health spending as share of the GDP was not stationary under none of the models. For pcHS indicator an inverse relationship is observed after the breaks, due to negative and highly significant coefficient of the both dummies. This finding indicates that major income level has not been corresponded with increases on the health public spending. This indicator has evolved since two quite different stages (see Figure 4). First, between 1940 and ends of the seventies, health spending exhibited a positive tendency, however, since the eighties it was downwards, and it starts to grow again by the twothousand years. As consequence the statistics reveal an inverse relationship. In fact, this result says much about the abandon of the government on health spending since country started a stage of trade opening.

Why health spending, as proportion of GDP, is not stationary? It is possible the presence of more than two structural changes, so the previous models cannot adequately identify the stationarity (see Figure 4). However, to test three or more structural breaks is out of this work, because it implies to consider a longer period or a database with more frequency, as quarters, for example. In any case, the empirical information constitutes an important limitation.

Life expectancy also was not stationary. In addition to the commented case of more than two structural breaks, it is possible that this result alludes at the nature of this health indicator: life expectancy is characterized by a uniform tendency to continuously grow along time (see Figure 2). By the contrary, the Mexican income level shows stages of increases that were interrupted by several and depth crises transforming the slope from positive to null and even negative for some years.

Estimated breakpoints are quite related to the main national events. For example, reforms on health are the 
reason for the breaks located by 1956, 1963 and 1969 (for the first reform), 1985 and 1989 (for the second reform) and 2002 to 2004 (for the third reform). Likewise, other breaks seem to respond to economic crises as the dates of 1983 and 1995.

Breaks for MMR correspond to 1995, a year defined by severe economic crisis, and 2002, where effects of the third reform to health system were felt. On the other hand, per capita health spending was firstly broken by 1956, a date very identified with the first reform, and the second one in 1983, which corresponds to the economic crisis of the eighties. Finally, child mortality rate estimated its first break around the first reform on health, while the 1989 break obeys to the economic crisis of 1986 and also to the decentralization process in the Mexican health system.

\section{CONCLUSIONS}

Almost none doubt exists about the relevance of an equilibrium relationship among health and income level to confront the social and economic problems of the population, due to both macroeconomic concepts are heavily linked. At the macroeconomic level the studies have been focused in to capture this connection through a production function, analyzing the causality direction and investigating the statistical properties of the time series.

This last vein of investigation has been recently quite relevant from the long-run analyses, because it allows examining the equilibrium path taking into account the almost inevitable regime shifts that dominate the long-run tendencies.

Due to several events featuring the Mexican economy the set of unit root tests without structural break was not able to find stationarity in the healthincome gap. This fact is reinforced by the evidence of stationarity with structural break estimated by the models that take into account the possibility of the breakpoints. The two health indicators that are widely related to mortality rates have the signs according with the theory: when income is increasing they are falling. In change, the health spending indicators estimate heterogeneous results. The per capita health spending (pcHS) is stationary around two broken trends, however, judging by the dummies coefficient, the income level had not improved this component of the government expenditure. According to the breakpoints this is observed since the country started the trade opening. This result deserves more investigation because the negative tendency in the per capita health spending could be partially explained by increases on the health spending of the people in the private sector and also by a policy of abandon of the health system by government, that is, a displacement effect could be happening. In particular, Knaul et al. (2007) find that private spending rose in Mexico since 1990, while Zurita and Ramirez (2003) estimate that private spending in Mexico was of 64 percent by 1995 and Sesma-Vázquez, Pérez-Rico, Martínez-Monroy and Lemus-Cardona (2005) also highlight a primacy of the private sector on the public one in health. Additional work seems necessary to confirm this hypothesis linking public and private spending in a time series model.

Differently, the health spending as share of GDP was not stationary. In this case, the huge fall in the public expenditure since the eighties has much to see. While levels of per capita income register gradual increments along the period, the public expenditure registers a negative tendency. Therefore, the unit root techniques assess the no existence of cointegration for this link. In addition, the trend of this indicator seems to be dominated by more than two breaks and if it is so, then the techniques conclude on non-stationarity. In any case, additional investigation seems to be necessary because of the importance for the country to advance on improving of the population health conditions. This observation is not a minor question; it should be a major concern for the government because some other countries of similar income than Mexico have reported best results in terms of health public spending. In addition, the budget cuts on health could be postponing the economic growth and affect the vulnerability of the population at the poverty, given the strong link among health indicators and income.

\section{ACKNOWLEDGEMENTS}

Authors acknowledge the financial support by the Autonomous University of Coahuila to carry out this project, at the participants of a congress on Seminar of Investigation realized in Saltillo, Mexico, and two anonymous referees for useful comments that helped to enrich the final version of this work.

\section{REFERENCES}

Acemoglu, Daron and Jhonson, Simon. 2007. "Disease and Development: the Effect of Life Expectancy on Economic Growth." Journal of Political Economy 115(6):925-985. http://dx.doi.org/10.1086/529000

Adeniyi, O. and Abiodun, L., 2011. "Health Expenditure and Nigerian Economic Growth." European Journal of Economics, Finance and Administrative Sciences 30(30):125-129. 
Arora, Suchit, 2001. "Health, Human Productivity, and Long-Term Economic Growth." The Journal of Economic History 61(3):699-749.

Barro, Robert. 1996. Health and Economic Growth, Cambrigde: Harvard University Press.

Bhargava, A. 1986. "On the Theory of Testing for Unit Roots in Observed Time Series." Review of Economic Studies 53:137-160. http://dx.doi.org/10.2307/2297634

Bloom, David, Canning, David and Sevilla, Jaypee. 2004. "The Effect of Health on Economic Growth: A Production Function Approach." World Development 32(1):1-13. http://dx.doi.org/10.1016/j.worlddev.2003.07.002

Boussalem, Fatima; Boussalem, Zina and Taiba, Abdelaziz. 2014. "The Relationship between Public Spending on Health and Economic Growth in Algeria: Testing for Co-integration and Causality." International Journal of Business and Management 2(3):25-39.

Bukenya, James. 2009. "Do Fluctuations in Health Expenditure Affect Economic Growth?" The Open Economics Journal 2:31-38.

Carrion-i-Silvestre, Josep L., 2005. "Health Care Expenditure and GDP: Are They Broken Stationary?" Journal of Health Economics 24(5):839-54. http://dx.doi.org/10.1016/j.jhealeco.2005.01.001

Carrion-i-Silvestre, Josep L., Artís, Manuel, and Sansó, Andreu. 2004. "Raíces Unitarias y Cambios Estructurales en las Macromagnitudes Españolas." Revista de Economía Aplicada, 12(35):5-27.

Chang, Koyin and Yung-Hsiang, Ying. 2006. "Economic Growth, Human Capital Investment, and Health Expenditure: A Study of OECD Countries." Hitotsubashi Journal of Economics 47(1):1-16.

Chen, Wen-Yi. 2013. "Do Caesarean Section Rates 'catch-up'? Evidence from 14 European Countries." Health Care Management Science 16(4):328-340. http://dx.doi.org/10.1007/s10729-013-9232-4

Dickey, David A., and Fuller, Wayne A. 1979. "Distribution of the Estimators for Autoregressive Time Series with Unit Root." Journal of American Statistical 74(366):427-431. http://dx.doi.org/10.2307/2286348

Elliot, Graham; Rothenberg, Thomas J., and Stock, James H. 1996. "Efficient Test for an Autoregressive Unit Root." Econometrica 64(4):813-836. http://dx.doi.org/10.2307/2171846

Frenk, Julio; Sepúlveda, Jaime; Gómez-Dantés, Octavio, and Knaul, Felicia. 2003. "Public Health Evidence-Based Health Policy: Three Generations of Reform in Mexico." The Lancet, 362(9396):1667-1671. http://dx.doi.org/10.1016/S0140-6736(03)14803-9

Fuchs, Victor R. 1972. "Front Matter, Essays in the Economics of Health and Medical Care." Pp. 1-22. In Essays in the Economics of Health and Medical Care edited by V. R. Fuchs. NBER: Columbia University Press.

German-Soto, Vicente. 2005. "Generación del Producto Interno Bruto Mexicano por Entidad Federativa, 1940-1992." El Trimestre Económico 72(3):617-653.

Grossman, Gene M. 1972. "On the Concept of Health Capital and the Demand for Health." The Journal of Political Economy 80(2):223-255.

http://dx.doi.org/10.1086/259880

Hernández-Laos, Enrique. 1992. Crecimiento Económico y Pobreza en México. México: UNAM.

Hernández-Laos, Enrique. 2000. "Crecimiento Económico, Distribución del Ingreso y Pobreza en México." Comercio Exterior 50(7):863-873.

Howitt, Peter. 2005. "Health, Human Capital, and Economic Growth: A Schumpeterian Perspective." Seminar Paper for the Pan American Health Organization.
Instituto Nacional de Estadística y Geografía (INEGI). 2009. Estadísticas Históricas de México, Aguascalientes: INEGI.

Instituto Nacional de Estadística y Geografía (INEGI). 2013. Banco de Información Económica, Aguascalientes: INEGI.

Jewell, Todd; Lee, Junsoo; Tieslau, Margie, and Strazicich Mark C. 2003. "Stationarity of Health Expenditures and GDP: Evidence from Panel Unit Root Tests with Heterogeneous Structural Breaks." Journal of Health Economics 22(2):31323. http://dx.doi.org/10.1016/S0167-6296(02)00122-4

Knaul, Felicia; Arreola-Ornelas, Héctor, and Méndez-Carniado, Oscar. 2005b. "Protección Financiera en Salud: México, 1992 a 2004." Salud Pública de México 47(6):430-439. http://dx.doi.org/10.1590/S0036-36342005000600007

Knaul, Felicia; Arreola-Ornelas, Héctor; Borja, Christian; MéndezCarniado, Oscar, and Torres, Ana C. 2003. "El Sistema de Protección Social en Salud de México: Efectos Potenciales sobre la Justicia Financiera y los Gastos Catastróficos de los Hogares." Pp. 275-292. In Caleidoscopio de la Salud. De la Investigación a las Políticas y de las Políticas a la Acción edited by F. M. Knaul and G. Nigenda. México: Funsalud.

Knaul, Felicia; Arreola-Ornelas, Héctor; Méndez-Carniado, Oscar, and Martínez, Alejandra. 2005a. "Justicia Financiera y Gastos Catastróficos en Salud: Impacto del Seguro Popular de Salud en México." Salud Pública de México 47(1):54-65.

Knaul, Felicia; Arreola-Ornelas, Héctor; Méndez-Carniado, Oscar; Bryson-Cahn, C.; Barofsky, J.; Maguire, R. and Sesma, S. 2007. "Las Evidencias Benefician al Sistema de Salud: Reforma para Remediar el Gasto Catastrófico y Empobrecedor en Salud en México." Salud Pública de México 49(1):70-87. http://dx.doi.org/10.1590/s0036-36342007000700010

Kumar, Bikash M. 2015. "Linkages between Health and Economic Growth in India: An Econometric Analysis." Journal of Business Management \& Social Sciences Research 4(1): 20-27.

Kwiatkowski, D., Phillips, P. C. B., Schmidt, P., and Shin, Y. 1992. "Testing the Null Hypothesis of Stationarity against the Alternative of a Unit Root." Journal of Econometrics 54(13):159-178.

http://dx.doi.org/10.1016/0304-4076(92)90104-Y

Lorentzen, Peter; McMillan, John, and Wacziarg, Romain. 2008. "Death and Development." Journal of Economic Growth 13(2):81-124. http://dx.doi.org/10.1007/s10887-008-9029-3

Lumsdaine, Robin L., and Papell, David. 1997. "Multiple Trend Breaks and the Unit Root Hypothesis." Review of Economics and Statistics 79(2):212-218. http://dx.doi.org/10.1162/003465397556791

Lustig, Nora. 2007. "Investing in Health for Economic Development: The Case of Mexico." Pp. 168-182. In Advancing Development: Core Themes in Global Economics edited by G. Mavrotas and A. Shorrocks. London: Palgrave Macmillan.

Mayer, David; Mora, Humberto; Cermeño, Rodolfo; Barona, Ana B. and Duryeau, Suzanne. 2003. "Salud, Crecimiento y Distribución del Ingreso en América Latina y el Caribe: Estudio de los Factores Determinantes y del Comportamiento Regional y Local." Pp. 3-34. In Invertir en Salud: Beneficios Sociales y Económicos edited by Organización Panamericana de la Salud. Washington: Organización Panamericana de la Salud.

Mehrara, Mohsen and Musai, Maysam. 2011. "Granger Causality between Health and Economic Growth in Oil Exporting Countries." Interdisciplinary Journal of Research in Business $1(8): 103-108$.

Merino, Gustavo. 2003. "Descentralización del Sistema de Salud en el Contexto del Federalismo". Pp. 195-208. In Caleidoscopio de la Salud. De la Investigación a las Políticas y de las Políticas a la Acción edited by F. M. Knaul and G. Nigenda. México: Funsalud. 
Montañés Antonio; Olloqui, Irene, and Calvo, Elena. 2005. "Selection of the Break in the Perron-Type Test." Journal of Econometrics 129:41-64. http://dx.doi.org/10.1016/j.jeconom.2004.09.003

Mushkin, Selma J. 1962. "Health As an Investment." Journal of Political Economy 70(5):129-157. http://dx.doi.org/10.1086/258730

Newey, Whitney and West, Kenneth. 1987. "A Simple Positive SemiDefinite, Heteroscedasticity and Autocorrelation Consistent Covariance Matrix." Econometrica 55(3):703-708. http://dx.doi.org/10.2307/1913610

Newhouse, Joseph P. 1977. "Medical Care Expenditures: A CrossNational Survey." Journal of Human Resources 12(1):115125. http://dx.doi.org/10.2307/145602

$\mathrm{Ng}$, Serena and Perron, Pierre. 1995. "Unit Root Tests in ARMA Models with Data-Dependent Methods for the Selection of the Truncation Lag." Journal of the American Statistical Association 90:268-281. http://dx.doi.org/10.1080/01621459.1995.10476510

$\mathrm{Ng}$, Serena, and Perron, Pierre. 2001. "Lag Length Selection and the Construction of Unit Root Test with Good Size and Power." Econometrica 69(6):1519-1554. http://dx.doi.org/10.1111/1468-0262.00256

Pekkurnaz, Didem. 2015. "Convergence of Health Expenditure in OECD Countries: Evidence from a Nonlinear Asymmetric Heterogeneous Panel Unit Root Test." Journal of Reviews on Global Economics 4:76-38. http://dx.doi.org/10.6000/1929-7092.2015.04.07

Perron, Pierre and Vogelsang, Timothy J. 1992. "Nonstationary and Level Shifts with an Application to Purchasing Power Parity." Journal of Business and Economic Statistics 10(3):301-320.

Phillips, Peter C.B., and Perron, Pierre. 1988. "Testing for a Unit Root in Time Series Regression." Biometrica 75(2):335-346. http://dx.doi.org/10.1093/biomet/75.2.335
Pinzon-Florez, Carlos E.; Reveiz, Ludovic; Idrovo, Alvaro J. and Reyes, Hortensia. 2014. "Gasto en Salud, la Desigualdad en el Ingreso y el Índice de Marginación en el Sistema de Salud de México." Revista Panamericana de Salud Pública 35(1):1-7.

Rao, R. Ramesh; Jani, Rohana, and Sanjivee, Puvanesvaran. 2008. "Health, Quality of Life and GDP: An ASEAN Experience." Asian Social Science 4(4):70-76.

Sesma-Vázquez, Sergio; Pérez-Rico, Raymundo; Martínez-Monroy, Tania, and Lemus-Carmona, Edith. 2005. "Gasto Privado en Salud por Entidad Federativa en México." Salud Pública de México 47(1):S27-S36.

Sirag, Abdalla; Adamu, Peter, and Norashidah, Mohamed, N. 2013. "An Assessment of Health Care and Economic Growth in Sudan: An ARDL Bound Testing Approach." Journal of Economics and Sustainable Development 4(16):5-14.

Tang, Chor F. (2012). "The Health-Income Nexus for Malaysia: ARDL Cointegration and Rao's F-Test for Causality." Asian Journal of Empirical Research 2(1):1-8.

Van Zon, Adriaan and Muysken, Joan. 2001. "Health and Endogenous Growth." Journal of Health Economics 20(2):169-185. http://dx.doi.org/10.1016/S0167-6296(00)00072-2

World Bank. 2014. Indicators of Health and Population, Washington World Bank.

Zivot, Eric and Andrews, Donald W. 1992. "Further Evidence on the Great Crash, the Oil-Price Shock, and the Unit Root Hypothesis." Journal of Business and Economic Statistics 10(3):251-270.

Zurita, Beatriz and Ramírez, Teresita. (2003). "Desempeño de Sector Privado de la Salud en México." Pp. 153-161 In Caleidoscopio de la Salud. De la Investigación a las Políticas y de las Políticas a la Acción edited by F. M. Knaul and G. Nigenda. México: Funsalud.

\section{DOI: http://dx.doi.org/10.6000/1929-7092.2016.05.11}

(c) 2016 German-Soto and Fuentes; Licensee Lifescience Global.

This is an open access article licensed under the terms of the Creative Commons Attribution Non-Commercial License (http://creativecommons.org/licenses/by-nc/3.0/) which permits unrestricted, non-commercial use, distribution and reproduction in any medium, provided the work is properly cited. 